\title{
The resolution of unintended pregnancy among female students at the University of Ghana, Legon
}

Angela El-Adas

Follow this and additional works at: https://knowledgecommons.popcouncil.org/departments_sbsr-rh

Part of the Demography, Population, and Ecology Commons, Family, Life Course, and Society Commons, International Public Health Commons, Medicine and Health Commons, and the Women's Health Commons How does access to this work benefit you? Let us know!

\section{Recommended Citation}

El-Adas, Angela. 2007. "The resolution of unintended pregnancy among female students at the University of Ghana, Legon." Accra: Population Council. 


\title{
The Resolution of Unintended Pregnancy among Female Students at the University of Ghana, Legon
}

\author{
Angela El-Adas \\ Regional Institute for Population Studies, University of Ghana, \\ Legon
}

September 2007

This study was funded by Population Council under Award No. I06.82G. The opinions expressed herein are those of the author and do not necessarily reflect the views of the Population Council. 


\section{TABLE OF CONTENTS}

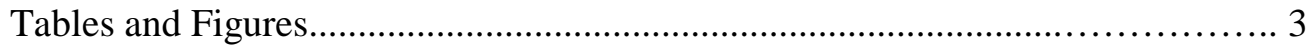

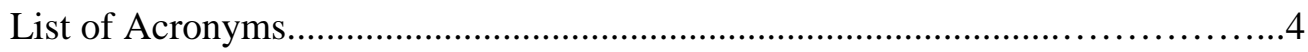

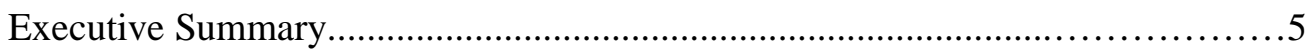

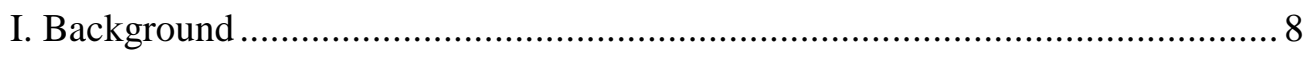

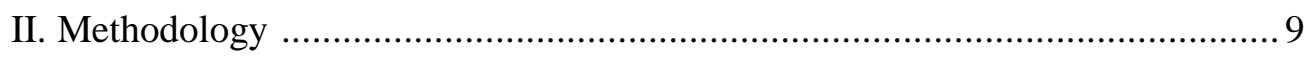

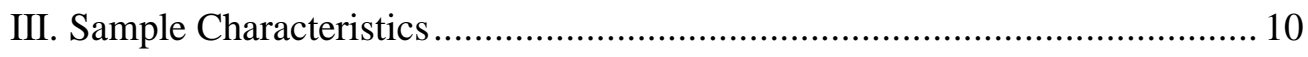

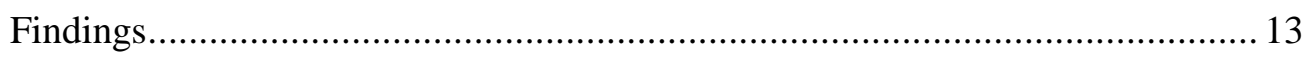

IV. Reproductive Health Knowledge ...................................................... 13

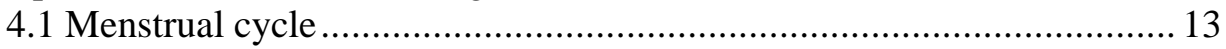

4.2 Sexually transmitted infections and HIV/AIDS ................................ 13

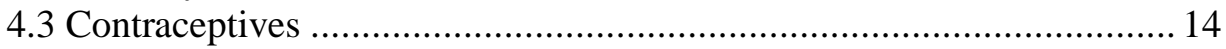

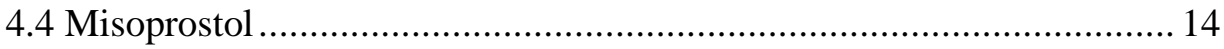

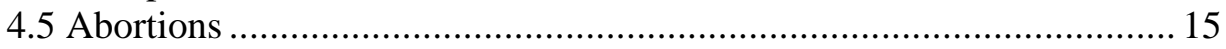

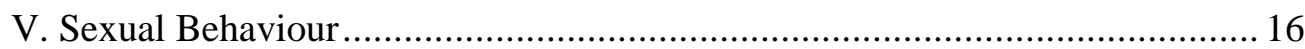

5.1 Sexual experience .............................................. 16

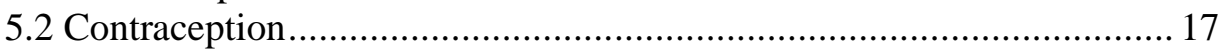

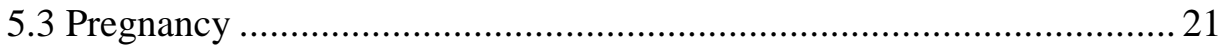

5.4 Experiences with HIV/AIDS .................................................. 21

VI. Factors influencing reproductive health decisions and sexual behaviour....... 22

6.1 Key persons/ communication/ discussions ....................................... 22

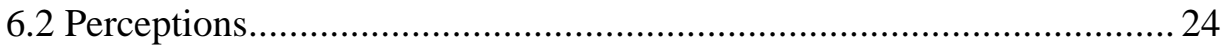

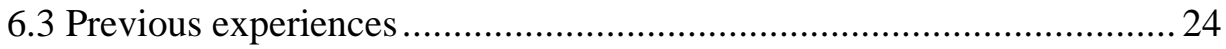

VII. Reproductive health services available to UG students ........................... 29

7.1 Family Planning services............................................................... 29

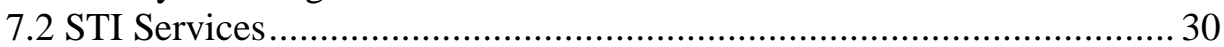

7.3 Abortion Services........................................................................ 30

VIII. Attitudes of students to reproductive health services............................... 31

IX. Resolution of unintended pregnancy ................................................... 32

9.1 What students think they will do if pregnant.................................... 33

9.2 What their (student) friends have done ........................................... 34

9.3 What students actually do when faced with unintended pregnancy ....... 35

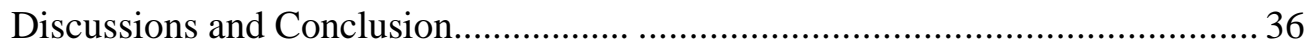

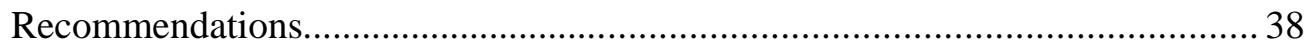

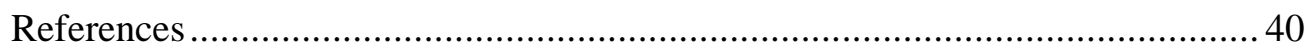

\section{TABLES \& FIGURES}

Table 1 Sample Characteristics of survey respondents ................................. 11 
Table 2 Knowledge of contraceptive methods by amrita status.

Table 3 Knowledge about abortion law in Ghana by marital status, sexual experience and sexual activity

Table 4 Percent distribution of female students who have ever had sex by contraceptive methods ever used 17

Table 5 Desire to get pregnant by current contraceptive use 17

Table 6 Perceived effect of getting pregnant by current contraceptive use 18

Table 7 Percentage distribution of women who have ever had sex current contraceptive method used 19

Table 8 Contraceptive method used at last sexual intercourse by marital status ... 19

Table 9 Decision to use a condom by type of partner ..................................... 20

Table 10 Key persons with whom students discuss RH issues ............................. 22

Table 11 Effect of discussions with partner on contraceptive use ....................... 22

Table 12 Students' perception of factors influencing a student's (hypothetical) decision to abort a pregnancy....................................... 23

Table 13 Factors influencing a (hypothetical) decision to have an abortion ........... 24

Table 14 Percentage distribution of women, who had ever had an abortion, by main reason given for seeking abortion...................................... 25

Table 15 What student would do if currently pregnant ...................................... 33

Table 16 Method by which some students obtained abortions .............................. 34

Table 17 Places where some students obtained abortions .................................. 34

\section{LIST OF ACRONYMS}




$\begin{array}{ll}\text { FGDs } & \text { Focus Group Discussions } \\ \text { VALCO } & \text { Volta Aluminium Company } \\ \text { SPSS } & \text { Statistical Package for Social Sciences } \\ \text { BA } & \text { Bachelor of Arts } \\ \text { BSc } & \text { Bachelor of Science } \\ \text { MA } & \text { Master of Arts } \\ \text { MSc } & \text { Master of Science } \\ \text { MPH } & \text { Master of Public Health } \\ \text { MPhil } & \text { Master of Philosophy } \\ \text { RH } & \text { Reproductive Health } \\ \text { STI } & \text { Sexually Transmitted Infection } \\ \text { HIV } & \text { Human Immunodeficiency Virus } \\ \text { AIDS } & \text { Acquired Immune Deficiency Syndrome } \\ \text { VCT } & \text { Voluntary Counseling and Testing } \\ \text { IUD } & \text { Intra Uterine Device } \\ \text { GDHS } & \text { Ghana Demographic and Health Survey } \\ \text { SSS } & \text { Senior Secondary School } \\ \text { PPAG } & \text { Planned Parenthood Association of Ghana } \\ \text { FP } & \text { Family Planning } \\ \text { ANC } & \text { Antenatal Care } \\ \text { PNC } & \text { Postnatal Care } \\ \text { PAC } & \end{array}$

\section{EXECUTIVE SUMMARY}

Little has been done to investigate the knowledge, attitudes and practices of university students, vis-à-vis unintended pregnancy probably because they are not considered a 
"deprived population" due to their prospective middle-class status. Female students in tertiary institutions of higher learning are at an age and in a social context, that makes them extremely susceptible to unintended pregnancy, and to the consequences of unsafe abortions. It is necessary to take steps aimed at reducing the incidence of repeated unwanted pregnancy and unsafe abortion among this group of "high risk" women.

This study sought to investigate the extent of knowledge that female students at the University of Ghana, Legon, have about preventing unwanted pregnancy and about abortions. It also sought to understand the factors that influence female student's decisions to access and utilize existing reproductive health services, including family planning, abortion and post-abortion services; as well as their attitudes towards these services. Data for this study are from a cross-sectional survey of a representative sample of 480 female students of childbearing age living in halls of residence at the University of Ghana. Focus group discussions were also held with 25 students to evoke relevant supplementary information.

The survey respondents were aged between 17 and 48 years, with $94.4 \%$ of them falling below age 30. At the time of the survey, $95.8 \%$ of the respondents were pursuing bachelors' degrees whilst $0.6 \%$ and $3.6 \%$ of them were respectively pursuing diplomas and masters' degrees.

Female students surveyed were fairly knowledgeable about most issues related to reproductive health, particularly sexually transmitted infections, and the availability of different contraceptive methods. However, their knowledge was inadequate especially with respect to the menstrual cycle and the safety (or risks) associated with the use of contraception. This knowledge is important in preventing unwanted pregnancy and may influence the decision or the need to have an abortion.

About 38\% (180) of all students interviewed had ever had sex. The median age at first sexual intercourse was 19.8 years, which is about $9 \%$ higher than the national average. Among sexually experienced women, $88 \%$ had ever used at least one contraceptive method during sexual intercourse, the male condom being by far the most common method ever used. Only 46 of the students in the study sample had ever been pregnant and had experienced a total of 110 pregnancies. Among these students, 19 had ever given birth (a total of 52 live births) and 31 had ever had an abortion (a total of 51 abortions), implying that $53 \%$ of all pregnancies did not result in a live birth. Only $40 \%$ of the terminations were done after entry into the University of Ghana. The decision to have an abortion is neither influenced by length of stay 
on campus nor year of study since admission to the UG. Rather, it is influenced by the students' academic aspirations, by student's fear of their parents reaction to a pregnancy, or by the fact that the child is 'unwanted'.

Even though 25 out of 38 students did not want to get pregnant then, only 11 students were using a contraceptive method when they last got pregnant.

Fully, $18 \%$ worry that they might be HIV positive. Among those who had ever had sex, 27\% worry that they might be HIV positive. Two out of five students (41\%) would like to undergo VCT and knew where to get tested; yet only $12 \%$ reported having had the test.

A previous discussion held with a husband/partner seemed to have a greater impact on reproductive health decisions than those held with a family member, friend, or health worker. Talking to a husband/partner at least once in the 12 months preceding the survey, led to a $150 \%$ increase in contraceptive use. Similarly, a student who had talked to her sexual partner about contraception at least once over the past twelve months was twice as likely to opt for an abortion, in case she got pregnant, compared to one who had had never discussed such issues with her partner. This decision remained the same irrespective of whether the relationship with her partner was sexual or not.

If faced with an unwanted pregnancy, $28 \%$ of sexually active students would prefer to abort the baby. Overall, $13 \%$ of all students interviewed would chose to have an abortion, $77 \%$ would not have an abortion, and $10 \%$ were not sure what decision they would make. A student's perception of which decision they would make if faced with an unintended pregnancy, was found to be influenced by their previous experiences including personal sexual and abortion experience, as well as having a friend who had succeeded in obtaining an abortion.

As expected, a student who had had a previous abortion was approximately four times as likely to have another abortion if faced with an unwanted pregnancy. Among those who had ever had sex, the likelihood of opting for an abortion decreased significantly with age. This decrease was most remarkable beyond age 24 . Thirty seven percent of all students knew where to get an abortion. All students who admitted to performing the abortion at home, on campus, or at a friend's house (10\%), had done so with a pill (unnamed) or with Cytotec, which they had acquired at a pharmacy. For many women who had ever had an abortion, 
more than one factor contributed to their decision. The commonest reasons given were 'still in school', 'fear of parents' and 'child unwanted'.

Almost every student interviewed stated that reproductive health counseling (98\%) and family planning services (80\%) are vital to students' health and well-being on campus. Even though more than one-third thought that excellent post abortion care (PAC) was important to help those who run into such problems, only $17 \%$ would like abortion services to be made available to students, since the provision of such services is likely to encourage promiscuity and unsafe sexual practices, and subsequently increase the incidence of abortion among students. Only $37 \%$ of those students, who favoured or strongly favoured the provision of abortion services, would actually opt for an abortion if they were to become pregnant as students.

The study suggests that unintended pregnancy is common among sexually active university students, mainly because of failure to consistently use effective contraceptive methods The high proportion of unintended pregnancy, half of which end up in abortions, is consistent with a desire for low fertility, given the opportunity costs, within an environment of significant sexual activity coupled with low contraceptive prevalence.

Female students should receive adequate reproductive health counseling, with emphasis on reducing fears and misconceptions about family planning. It would be helpful if male students and other partners of female students are involved in education and counseling programs. This is because they have a major influence on female students' contraception and abortion decisions. The provision of high quality, yet affordable student friendly reproductive health facilities is vital. These should be easily accessible and preferably integrated with other services to ensure confidentiality and avoid stigmatization.

\section{BACKGROUND}

Tertiary institutions across the globe are known to be venues of significant sexual activity. University students who are at the cross-roads of adulthood, away from home, and for many, finally in a context of no behaviour supervision and in settings that provoke and promote 
intellectual inquisitiveness, generally feel inclined to experiment in arenas they may have hitherto been told were the preserve of adults. Female students in tertiary institutions of higher learning are at an age and in a social context ${ }^{1}$ that makes them extremely susceptible to unintended pregnancy, and to the consequences of unsafe abortions ${ }^{2}$, given the prevailing conditions for abortions.

Little has been done to investigate the knowledge, attitudes and practices of university students, vis-à-vis unintended pregnancy probably because they are not considered a "deprived population" due to their prospective middle-class status. Particularly in the developing world, the opportunity costs— to the individual and to society-of unintended pregnancies are high. For the miniscule segment of the female population that makes it to the university level, and who are role models to subsequent generations of females, allowing pregnancy to retard their progress when they are so close to achieving their ultimate goals, and after paying as high a cost as they and society have had to, is generally not an option.

In a society where safe abortions are not generally available, and people have to resort to clandestine, illicit, and unproven techniques, the health and mortality implications of unintended pregnancies should be worrisome ${ }^{3}$, and particularly so for this young, "high-risk" group, who also risk considerable social sanction if they have abortions. It is precisely the high social and individual cost that makes this study of a group not otherwise considered "high-risk" imperative. It is important to get a wide view of what students think about unintended pregnancies, how they prevent, deal with and resolve these, and what options they know and consider in resolving unintended pregnancy.

This study sought to investigate the extent of knowledge that female students at the University of Ghana (UG), Legon, have about preventing unwanted pregnancy and about abortions. It also sought to understand the factors (societal and familial factors, as well as personal beliefs and aspirations) which influence female students' decisions about preventing unwanted pregnancy and about abortions; as well as utilization of existing family planning services, including abortion and post-abortion services, and their attitudes towards these services. The study also sought to assess the types of contraceptive methods utilized by highly educated Ghanaian women. Findings are meant to provide the necessary baseline information for further research endeavours, as well as inform the development of much needed Sexual and Reproductive Health programmes that address the needs of this vulnerable sub-population in Ghana and the rest of Africa. 


\section{METHODOLOGY}

Data for this study is from a cross-sectional survey of a representative sample of female students of childbearing age living in halls of residence at the University of Ghana (UG), as well as from focus group discussions, which helped to evoke relevant supplementary information. The UG has a population of 30,000 students, of which females constitute approximately 12,000 . The total resident female population (4378 students) formed the target population. The total number of female occupied rooms was used as the initial sampling frame to select a sample of 500 rooms. These were proportionately distributed over the eight halls of residence which house female students on campus, based on the total female populations of these halls. These include Volta, Legon, Jubilee, Akuafo, and Mensah Sarbah halls, and the International Students and Graduate Students (VALCO) Hostels. Volta Hall is the only all-female hall of residence at the University of Ghana. One student was interviewed from each sampled room.

A semi-structured questionnaire was used, comprising both close-ended and open-ended questions. Topics covered include basic socio-demographic characteristics of the study population, knowledge of reproductive health issues including methods for preventing unwanted pregnancies, the use of induced abortion as an option for terminating an unwanted pregnancy, and student's knowledge about, as well as use of abortion and post- abortion services. Students who have used any reproductive health services were asked about their experiences with the health services received. Questions, for which prior research was limited, were asked in open-ended format, and respondents were given the opportunity to give multiple responses.

Beyond the 500 female students who participated in the survey, a total of 24 students were randomly selected from the resident female population for participation in focus group discussions (FGDs). Four focus groups were formed comprising 5 to 6 female students each. These were stratified by age, into two groups each of women under 30 years and women 30 years and over. Because FGDs evoke more generalized or communal (versus individualized) perspectives, participants were able to interact and communicate rather freely about issues regarding the sexuality of students, use of contraceptive methods, access to and use of family planning methods other than "recognized and accepted methods". These discussions covered hypothetical and real-life situations which highlighted students' inclination to put themselves at risk of unintended pregnancies and hence, the subsequent need to resort to induced abortions, the individual and social factors which influence these decisions, as well as family 
planning services (including abortion and post-abortion services) known to, and/or accessed by students on campus. Discussions also covered the current abortion law in Ghana.

All interviews and focus group discussions were conducted in English. Survey interviewers and FGD moderators had prior interviewing experience. A four-day training workshop was held to explain the study objectives as well as ethical issues to the field workers, and to train them to comfortably use the study instruments prior to data collection. Training included a strong emphasis on putting the students at ease when asking sensitive questions. During training, interviewers reviewed the questionnaire item-by-item and engaged in practice and mock interviews. For open-ended questions, interviewers were trained to probe responses and record the response verbatim. Interviewers paid up to three visits to locate and interview an eligible student from a sampled room.

Participation in this study was voluntary and uncompensated. Informed consent was obtained from all respondents after they had read a written introduction to the study.

Each FGD did not exceed 1.5 hours' duration, and was audio-recorded with all participants' consent. Data were entered using Epi-Data and later converted to SPSS for analysis.

In addition to these interviews, a list of all reproductive health service providers utilized by female students on campus was compiled based on the responses obtained from the individual student interviews. Interviewers visited the sites on campus, where they approached the head administrator, introduced themselves and the study, and asked for informed consent before administering the survey instruments.

\section{SAMPLE CHARACTERISTICS}

A total of 480 female students aged 17 to 48 were interviewed, translating into a response rate of $96 \%$. This is consistent with that of an emergency contraception study conducted at the UG in $2001^{4}$ using similar methods of sampling and data collection. As depicted in Table 1 below, majority of the respondents were in the age group $20-24$ years $(68.1 \%)$ and less than $5 \%$ of the respondents were 30 years or above. Overall, $94.4 \%$ of the respondents were below age 30 .

Most of the respondents (89.4\%) had only completed secondary school education at the time of entering the university. The other respondents had earned diplomas, bachelors or professional degrees before enrolling for their current programmes of study. At the time of 
the survey, $95.8 \%$ of the respondents were pursuing bachelors' degrees, $0.6 \%$ of them were pursuing diplomas and $3.6 \%$ were pursuing masters' degrees.

Nearly ninety-five (94.6\%) percent of the survey respondents had never been married. The rest had either been married before $(0.8 \%)$ or were currently married $(4.6 \%)$.

The majority of respondents were Akan, Ga/Dangme or Ewe. Respondents from other ethnic groups made up $9.6 \%$ of the sample. They included the Guan, Mole-Dagbani, Grussi, Gruma and Hausa ethnic groups. The non-Ghanaian group was comprised largely of students from other West African countries.

Christians made up $92 \%$ of the interviewed sample. The rest were either Moslem, atheist or belonged to other religions. 
Table 1: Characteristics of survey respondents

\begin{tabular}{|c|c|c|}
\hline Variable & $\begin{array}{l}\text { Number } \\
(\mathrm{n}=480)\end{array}$ & Percentage \\
\hline Hall of residence & 91 & \\
\hline $\begin{array}{l}\text { Volta } \\
\text { Legon }\end{array}$ & $\begin{array}{l}91 \\
90\end{array}$ & $\begin{array}{l}19.0 \\
18.8\end{array}$ \\
\hline Mensah Sarbah & 111 & 23.1 \\
\hline Akuafo & 94 & 19.6 \\
\hline Jubilee & 47 & 9.8 \\
\hline International Students' Hostel & 31 & 6.5 \\
\hline Graduate (VALCO) Hostel & 16 & 3.3 \\
\hline Type of hall & & \\
\hline Female only & 91 & 19.0 \\
\hline Mixed & 389 & 81.0 \\
\hline Years of residence on campus & & \\
\hline One & 220 & 45.8 \\
\hline Two & 118 & 24.6 \\
\hline Three & 83 & 17.3 \\
\hline Four & 51 & 10.6 \\
\hline Five or more & 8 & 1.7 \\
\hline Age category & & \\
\hline Less than 20 & 84 & 17.5 \\
\hline 20 to 24 & 327 & 68.1 \\
\hline 25 to 29 & 42 & 8.8 \\
\hline 30 plus & 22 & 4.6 \\
\hline Missing & 5 & 1.0 \\
\hline Educational attainment & & 894 \\
\hline $\begin{array}{l}\text { Decondary/s.SS } \\
\text { Diploma }\end{array}$ & $\begin{array}{r}429 \\
18\end{array}$ & $\begin{array}{r}89.4 \\
3.8\end{array}$ \\
\hline First Degree & 25 & 5.2 \\
\hline Professional & 8 & 1.6 \\
\hline Current programme & & \\
\hline Diploma & 3 & 0.6 \\
\hline Bachelors (BA, BSc) & 460 & 95.8 \\
\hline Masters (MA, MSc, MPH, MPhil) & 17 & 3.6 \\
\hline Marital status & & \\
\hline Never married & 454 & 94.6 \\
\hline Formerly married & 21 & 4.4 \\
\hline Currently married (check figures in other columns) & 5 & 1.0 \\
\hline Ethnicity & & \\
\hline Akan & 267 & 55.6 \\
\hline $\mathrm{Ga} /$ Dangme & 70 & 14.6 \\
\hline Ewe & 65 & 13.5 \\
\hline Other Ghanaian & 46 & 9.6 \\
\hline Non- Ghanaian & 32 & 6.7 \\
\hline Religion & & \\
\hline Catholic & 90 & 18.8 \\
\hline Protestant & 155 & 32.3 \\
\hline Pentecostal/Charismatic & 198 & 41.3 \\
\hline Moslem & 19 & 4.0 \\
\hline Other & 18 & 3.8 \\
\hline
\end{tabular}

\section{FINDINGS}




\section{REPRODUCTIVE HEALTH KNOWLEDGE}

Female students surveyed were fairly knowledgeable on most issues related to reproductive health (RH). This knowledge is important in preventing unwanted pregnancy and may influence the decision or the need to have an abortion.

\subsection{Menstrual cycle}

A table of scores was prepared for seven different questions regarding knowledge of the menstrual cycle i.e., menstruation, ovulation, safe and fertile periods, etc. A correct response to any of the above questions was given a full score of 2. A partially correct response was scored as 1 and a wrong response was scored 0 . After computing a table of scores, the least possible score was 0 and the greatest possible score was 14. An aggregate score was categorized as follows: scores 5 and below (inadequate knowledge) scores 6-10 (partial knowledge) and scores 11 and above (good knowledge of the menstrual cycle). About threequarters $(76.5 \%)$ of the students had partial knowledge of the menstrual cycle; a further $22.7 \%$ had inadequate knowledge (mostly wrong answers) of the menstrual cycle. Only $0.8 \%$ (4 students) had good knowledge of the menstrual cycle. It was gratifying to note that $93.5 \%$ of all students interviewed knew that a woman can get pregnant the first time she has sexual intercourse.

\subsection{Sexually transmitted infections and HIV/AIDS}

With the exception of 1 student, all students interviewed knew about at least 1 sexually transmitted infection (STI) while $93 \%$ could mention at least one physical sign of STIs. Over 90\% of respondents mentioned gonorrhoea (95.8\%), HIV/AIDS (94.4\%) and Syphilis $(92.3 \%)$ as the STIs they know of. Approximately half of all respondents mentioned genital discharge, genital itch, and pain on urination as physical signs of STIs. Similarly, $45.1 \%$ of respondents knew various signs and symptoms of HIV/AIDS. Of the 7\% who could not mention any sign of STI, majority had never been married $(96 \%)$ or had never had sex $(66 \%)$.

When asked about ways to prevent HIV/AIDS, students commonly spoke about sexual behaviour rather than transmission through shared items or sharps. Students who were sexually experienced (had ever had sex) were more likely (52.2\%) to know that condoms are effective in preventing HIV/AIDS, as compared to those who had never had sex $(28.3 \%)$. The majority of female students who have ever had sex $(81.1 \%)$ knew where to get voluntary counselling and testing (VCT) for HIV. 


\subsection{Contraceptives}

Students were asked if they had ever heard, seen or read about ways or methods that sexual partners could use to delay or avoid a pregnancy. The students were allowed to respond spontaneously (i.e. without prompting or description of any method). All but three students who were never married and who had never had sex responded in the affirmative, making knowledge of contraceptive methods almost universal (refer to Table 2 below). Ever married students were more knowledgeable about long term methods, specifically injectables, implants and intra-uterine devices (IUDs). Similarly, emergency contraception was mentioned more frequently by those students who had ever had sex than those who had never had sex.

Table 2: Knowledge of contraceptive methods by marital status

*Chi square test significant at $\mathrm{p}<0.05$ comparing ever married to never married

** Chi square test significant at $\mathrm{p}<0.05$ comparing ever had sex to never had sex

\begin{tabular}{|c|c|c|c|c|c|c|}
\hline \multirow[t]{3}{*}{ Method } & \multirow{3}{*}{$\begin{array}{l}\text { All } \\
\text { Women }\end{array}$} & \multirow{2}{*}{\multicolumn{2}{|c|}{ Marital status }} & \multicolumn{3}{|c|}{ Never Married } \\
\hline & & & & \multicolumn{2}{|c|}{ Ever had sex } & \multirow{2}{*}{$\begin{array}{l}\text { Never had } \\
\text { sex }\end{array}$} \\
\hline & & $\begin{array}{l}\text { Ever } \\
\text { Married } \\
(n=26)\end{array}$ & $\begin{array}{l}\text { Never } \\
\text { Married } \\
(n=454)\end{array}$ & $\begin{array}{l}\text { !Sexually } \\
\text { active } \\
(\mathrm{n}=62)\end{array}$ & $\begin{array}{l}\text { Not } \\
\text { sexually } \\
\text { active } \\
(n=92)\end{array}$ & \\
\hline At least one method & $99.4 * * *$ & 100.0 & 100.0 & 100.0 & 100.0 & 99.0 \\
\hline \multicolumn{7}{|l|}{ Modern methods } \\
\hline Female Sterilization & 21.0 & 11.5 & 21.3 & 16.1 & 19.6 & 23.2 \\
\hline Male Sterilization & 32.1 & 19.2 & 32.9 & 32.3 & 33.7 & 32.7 \\
\hline Pill & 82.6 & 84.6 & 82.4 & 80.6 & 82.6 & 82.8 \\
\hline Emergency Contraception & 23.9 & 19.2 & 24.2 & 27.4 & 38.0 & $19.2 * *$ \\
\hline Injectables & 27.3 & 53.8 & $25.8 *$ & 21.0 & 26.1 & 26.6 \\
\hline Implants & 15.5 & 42.3 & $14.0^{*}$ & 19.4 & 13.0 & 13.1 \\
\hline IUD & 37.3 & 69.2 & $35.6^{*}$ & 24.2 & 34.8 & 38.0 \\
\hline Male Condom & 88.1 & 92.3 & 87.8 & 90.3 & 84.8 & 88.2 \\
\hline Female Condom & 83.0 & 84.6 & 82.9 & 79.0 & 83.7 & 83.5 \\
\hline Diaphragm & 12.2 & 23.1 & 11.6 & 14.5 & 15.2 & $9.8 * *$ \\
\hline Foam/Jelly & 14.9 & 26.9 & 14.2 & 16.1 & 14.1 & 13.8 \\
\hline \multicolumn{7}{|l|}{ Traditional methods } \\
\hline Lactational Amenorrhoea & 1.7 & 11.5 & $1.1^{*}$ & 1.6 & 2.2 & 0.7 \\
\hline Rhythm/Periodic abstinence & 23.7 & 34.6 & 23.1 & 29.0 & 23.9 & 21.5 \\
\hline Withdrawal & 25.2 & 15.4 & 25.6 & 29.0 & 31.5 & 23.2 \\
\hline Herbs & 1.9 & 3.8 & 1.8 & 1.6 & 2.2 & 1.7 \\
\hline
\end{tabular}

*** 3 students had no knowledge of contraceptive methods

! 'Sexually active' refers to students who had had sex in the 4 weeks preceding the survey 


\subsection{Misoprostol}

Only 42 female students had ever heard about Misoprostol/Cytotec. Four students knew it was a tablet but did not know what it was meant for and another 2 admitted that it was an ulcer drug. The others knew about the effects of the drug on the reproductive system (i.e., a drug to regulate menstrual flow - 2 students, to induce labour - 3 students and to terminate pregnancy - 29 students). Of the 42 students, 33 knew a pharmacy and 4 knew a hospital where they could obtain Misoprostol.

\subsection{Abortions}

The most commonly mentioned reproductive health problems experienced by female university students were STIs (69.6\%), unintended pregnancy (41.8\%) and abortions (36.9\%). These were followed by post abortion complications (12.4\%) and rape (6.0\%) respectively. Students with some sexual experience were more likely to mention unintended pregnancy and abortion, whilst those with no sexual experience mentioned STIs.

From Table 3 below, it is clear that sexual experience makes a difference in a student's knowledge about abortion, especially with respect to places where abortions are offered and/or where a student could seek for an abortion.

Only $16.5 \%$ of all respondents would attempt to outline the abortion law ${ }^{5}$. Less than onethird of these respondents simply stated that abortion is a criminal offence. However, Table 3 suggests that just about $14 \%$ of the students interviewed knew that abortions are legal in Ghana under certain conditions. The most commonly mentioned condition for which an abortion could be performed legally was, "if the pregnancy could cause risk to the physical health of the mother". This may actually be a reflection of what pertains in clinical practice, rather than a reflection of theoretical knowledge of the law.

Knowledge of post abortion complications was almost universal. A significant proportion mentioned secondary infertility (70.5\%), death (60.8\%), severe bleeding (38.6\%), and trauma, or damage to or loss of the womb (30\%). Very few $(6.3 \%)$ mentioned the psychological effects of having an abortion. Overall, only $36.3 \%$ (174) of all students interviewed knew of at least one place where abortion services are offered. 
Table 3: Knowledge about the abortion law in Ghana by marital status, sexual experience and sexual activity

\begin{tabular}{|c|c|c|c|c|c|c|}
\hline \multirow[t]{2}{*}{ Question asked } & \multicolumn{2}{|c|}{ Marital Status } & \multicolumn{2}{|c|}{ Ever had Sex } & \multicolumn{2}{|c|}{ Sexual Activity } \\
\hline & $\begin{array}{l}\text { Ever } \\
\text { Married } \\
(n=26)\end{array}$ & $\begin{array}{l}\text { Never } \\
\text { married } \\
(n=454)\end{array}$ & $\begin{array}{l}\text { Yes } \\
(n=180)\end{array}$ & $\begin{array}{l}\text { No } \\
(\mathrm{n}=300)\end{array}$ & $\begin{array}{l}\text { Sexually } \\
\text { Active } \\
(n=76)\end{array}$ & $\begin{array}{l}\text { Not } \\
\text { Sexually } \\
\text { Active } \\
(n=104)\end{array}$ \\
\hline \multicolumn{7}{|c|}{$\begin{array}{l}\text { Are abortions legal or illegal in } \\
\text { Ghana? }\end{array}$} \\
\hline Illegal & 65.4 & 66.4 & 68.4 & 65.1 & 60.5 & 74.0 \\
\hline Legal & 7.7 & 5.1 & 5.0 & 5.4 & 7.9 & 2.9 \\
\hline Conditional & 15.4 & 14.4 & 14.4 & 14.4 & 15.8 & 13.5 \\
\hline Don't Know & 11.5 & 13.9 & 12.2 & 14.8 & 115.8 & 9.6 \\
\hline \multicolumn{7}{|c|}{$\begin{array}{l}\text { Do you know what the law says } \\
\text { about abortion in Ghana? }\end{array}$} \\
\hline Yes & 34.6 & $16.5^{*}$ & 24.7 & $13.1^{*}$ & 22.7 & 26.2 \\
\hline No & 65.4 & $82.6^{*}$ & 75.3 & $85.5^{*}$ & 77.3 & 73.8 \\
\hline \multicolumn{7}{|c|}{$\begin{array}{l}\text { What does the law say about } \\
\text { abortion in Ghana? } * * *\end{array}$} \\
\hline Correct response & 0.0 & $1.3 *$ & 0.0 & $2.5^{*}$ & 0.0 & 0.0 \\
\hline Partially correct response & 100.0 & $93.3 *$ & 100.0 & $87.5^{*}$ & 100.0 & 100.0 \\
\hline Wrong response & 0.0 & $2.7 *$ & 0.0 & $5.0^{*}$ & 0.0 & 0.0 \\
\hline \multicolumn{7}{|c|}{$\begin{array}{l}\text { Do you know any place(s) } \\
\text { where abortion services are } \\
\text { offered? }\end{array}$} \\
\hline Yes & 69.2 & $35.1 *$ & 53.7 & $27.1 *$ & 62.7 & 47.0 \\
\hline No & 30.8 & $64.2 *$ & 45.7 & $72.2 *$ & 37.3 & 52.0 \\
\hline
\end{tabular}

*There was a significant difference between responses given by the two categories of the independent variable.

*** This question was only asked of respondents who had said they knew what the law says about abortion in Ghana. Various dictates of the Criminal Offences Act, 1960, Act 29, were grouped into 4 major components, namely:

1. Criminal implications of the law / the legality of abortion being conditional

2. Conditions under which the pregnancy occurs

3. Conditions considering health of mother or foetus

4. Conditions considering the health institution

A correct response required that a respondent mention at least 1 dictate under each of all 4 components. A response was partially correct if it covered at least 1 out of the 4 components and wrong if none of the dictates were stated correctly.

\section{SEXUAL BEHAVIOUR}

\subsection{Sexual experience}

About 38\% (180 students) of all students interviewed had ever had sex. The median age at first sexual intercourse was 19.8 years, which is about $9 \%$ higher than the national average (GDHS, 2003) ${ }^{6}$. Close to $5 \%$ reported having sexual intercourse by age 15 . Sexual experience did not differ significantly by ethnic and religious backgrounds. 
Of all students who had ever had sex, $54.5 \%$ had been sexually active in the four weeks preceding the survey. As expected, sexual activity was higher among married students $53.8 \%$ of married students were currently sexually active compared to $40.3 \%$ of unmarried students. Again, among all students who had ever had sex, $42.9 \%$ of those aged less than 20 years were currently sexually active as were $41.9 \%$ of those $20-24$ years old, $29.5 \%$ of those 25-29 years old and $54.5 \%$ of those over 30 years old.

Among unmarried students, $33.9 \%$ were sexually experienced. The majority (83\%) of female university students currently in a sexual relationship were not married to their partners. Of these unmarried students, only $57 \%$ had used a condom at last sex. Also, approximately $25 \%$ of students who were sexually active did not have a regular sex partner while $70 \%$ had only one regular sex partner. Of the 4 students who had more than one regular partner, 3 had 2 partners each and 1 student had 4 partners. Eleven students had had one sexual encounter with a casual partner within the 4 weeks preceding the survey and 2 students had had such encounters with 2 casual partners each. All married students admitted to having only one regular partner.

Apart from sexually active students (42.2\% of students had had sex in the past 4 weeks), a further $27.8 \%$ had had sexual intercourse within the last year, and $12.8 \%$ could not remember the last time they had sex.

A cross tabulation of age at first sex with current age group revealed that students aged 24 years and below had their first sexual experience much earlier than students in the 25-29 years age group. Over half $(57.1 \%)$ of students aged $<20$ years and $33.1 \%$ of those aged $20-$ 24 years had had sex by age 19 (at or before age 18); among those aged 30 years and above, the percentage that had had sex by age 19 was 24.0 . No student in the age group $25-29$ had had a sexual encounter by that age. It is quite obvious from the experiences of the different age cohorts that university students are progressively engaging in sexual activities at much younger ages $(p=0.026)$.

\subsection{Contraception}

Among sexually experienced female students, $88 \%$ had ever used one or more contraceptive methods during sexual intercourse; male condom was by far the most common method ever used (see Table 4). It is worth noting that emergency contraception had been used by $27 \%$ of these women as a method of choice. Generally, the relatively large proportion of students that 
relied on less effective methods such as periodic abstinence, withdrawal and other traditional methods could contribute disproportionately to rates of unintended pregnancy.

Table 4: Percent distribution of female students who have ever had sex by contraceptive methods ever used

\begin{tabular}{|l|r|}
\hline Method & \multicolumn{2}{|c|}{$\begin{array}{c}\text { Percent who have ever used a method } \\
\text { among those who have ever had sex } \\
(\mathrm{n}=180)^{*}\end{array}$} \\
\hline At least one method & \multicolumn{1}{|c|}{} \\
\hline Modern methods & 88.0 \\
\hline Female Sterilization & 0.6 \\
\hline Oral Contraceptive Pill & 19.0 \\
\hline Emergency Contraception & 27.2 \\
\hline Injectables & 3.8 \\
\hline Implants & 2.5 \\
\hline IUD & 4.4 \\
\hline Male Condom & 80.4 \\
\hline Female Condom & 8.9 \\
\hline Spermicide/Foam/Jelly & 8.9 \\
\hline Traditional methods & \\
\hline Lactational Amenorrhoea & 1.3 \\
\hline Rhythm/Periodic Abstinence & 34.2 \\
\hline Withdrawal & 30.4 \\
\hline Herbs & 1.3 \\
\hline Other & \\
\hline Occult Protection & 0.6 \\
\hline
\end{tabular}

More than half of the female students who said they did not want to get pregnant were not using any contraceptive method. On the other hand, $46 \%$ of those who wanted to get pregnant were using some contraceptive method. This suggests that the students' contraceptive behaviour did not match their fertility desires (Table 5).

Table 5: Desire to get pregnant by current contraceptive use

\begin{tabular}{|l|r|r|}
\hline Desire to get pregnant at time of study & $\begin{array}{l}\text { Percent currently } \\
\text { using contraception }\end{array}$ & Number \\
\hline No & 49.7 & 155 \\
\hline Yes & 46.2 & 13 \\
\hline Total & 49.4 & 168 \\
\hline
\end{tabular}

Again, female students were asked whether it would be a big problem, a small problem or no problem if they discovered they were pregnant. Approximately 53\% of those who responded 
to the question indicated that it would be a big problem and of these, $51.1 \%$ were not using any contraceptive method (Table 6).

Table 6: Perceived effect of getting pregnant by current contraceptive use

\begin{tabular}{|l|r|r|r|}
\hline \multirow{2}{*}{$*$ Perceived effect of pregnancy } & \multicolumn{2}{|c|}{ Current use of contraception } & Percent of total \\
\cline { 2 - 4 } & Not currently using & Currently using & $(\mathrm{n}=174)$ \\
\hline Big problem & 51.1 & 48.9 & 52.9 \\
\hline Small problem & 47.6 & 52.4 & 12.1 \\
\hline No problem & 40.0 & 60.0 & 23.0 \\
\hline Can't get pregnant/not having sex & 81.0 & 19.0 & 12.1 \\
\hline
\end{tabular}

* Significant difference between groups at $\mathrm{p}<0.05$

Despite the students' desire not to get pregnant, a substantial proportion of those who had ever had sex $(52.2 \%)$ were, at the time of the study, not using any method of family planning. The details of contraceptive use are depicted in Table 7 below. It became clear from the FGDs that using contraceptives, especially hormonal methods, would subsequently lead to difficulty in conception. A student would rather have an abortion and get pregnant again than risk the side effects of using contraceptives, as demonstrated in the following statements:

“.......my belief is that if you've never given birth and you use contraceptives, most of them have side effects, for me it is not advisable to try it. When I am having discussions with my roommates, they also say the same thing. Especially injectables, if it stays in you for a long time, it will have some side effects; it will cause problems ... especially if you haven't given birth

"Some people also think we have different kinds of contraception which include the abortion also, so they do away with all others thinking that if you use the pill, the foaming tablet, etc, you may not be able to give birth in the future, so why not go my free way and abort? After I've picked a seed and gone to remove it, I'll pick another one. 
Table 7: Percentage distribution of women who have ever had sex by current contraceptive method used

\begin{tabular}{|l|r|}
\hline Method & \multicolumn{2}{|c|}{$\begin{array}{c}\text { Percent currently using a method } \\
\text { among those who have ever had sex } \\
(\mathrm{n}=180)\end{array}$} \\
\hline At least one method & 47.8 \\
\hline Modern methods & \\
\hline Oral contraceptive pill & 7.0 \\
\hline Emergency Contraception & 8.1 \\
\hline Injectables & 4.7 \\
\hline Implants & 1.2 \\
\hline Male Condom & 74.3 \\
\hline Spermicide/Foam/Jelly & 3.5 \\
\hline & \\
\hline Traditional methods & 1.2 \\
\hline Rhythm/Periodic abstinence & \\
\hline
\end{tabular}

The majority (83\%) of female students who were in a sexual relationship at the time of the study were not married to their partners. Of these students, approximately $60 \%$ had used a condom either alone or in combination with some other method at the last sex. Similarly, $27 \%$ of all female students who were currently married used a condom at the last sexual intercourse (Table 8). Condom use is lowest among the under twenties (33.3\%), and highest (62.1\%) among the 20-24 year age group.

Table 8: Contraceptive method used at last sexual intercourse by marital status

\begin{tabular}{|l|r|r|}
\hline Contraception & Currently married & $\begin{array}{c}\text { Currently not } \\
\text { married } \\
(\mathrm{n}=109)\end{array}$ \\
\hline Used condom alone & 13.6 & 52.3 \\
\hline Used other method & 40.9 & 21.1 \\
\hline Combined condom with other method & 13.6 & 7.3 \\
\hline No contraception & 40.9 & 16.5 \\
\hline Missing & - & 2.8 \\
\hline Total & 100.0 & 100.0 \\
\hline
\end{tabular}

Out of 14 female students who had had a casual sexual relationship in the last four weeks, 8 of them had also had sex with a regular partner. In two of these cases, a condom had been used with their regular partner, but not with the casual partner. It appears that female students take responsibility in deciding whether or not a condom is used during sexual intercourse. In the majority of cases the decision was either a joint one or had been made by the female partner (Table 9). 
Table 9: Decision to use a condom by type of partner

\begin{tabular}{|l|l|l|l|l|}
\hline Type of partner at last sex & \multirow{2}{*}{$\begin{array}{l}\text { Percent who used a } \\
\text { condom at last sex }\end{array}$} & & \multicolumn{3}{|l|}{$\begin{array}{l}\text { Person making the decision to use condom at } \\
\text { last sex }\end{array}$} & Myself & My partner & Joint decision \\
\cline { 3 - 5 } & & 12.5 & 25.0 & 62.5 \\
\hline Casual partner $(\mathrm{n}=14)$ & 57.1 & & 16.9 & 57.7 \\
\hline Regular partner $(\mathrm{n}=129)$ & 55.0 & 25.4 & & 58.2 \\
\hline Total $(\mathrm{n}=141)$ & 56.0 & 24.1 & 17.7 & \\
\hline
\end{tabular}

\subsection{Pregnancy}

Only 46 of the students in the sample had ever been pregnant and had had a total of 110 pregnancies. Among these students, 19 had ever given birth (a total of 52 live births) and one student was four months pregnant with her first pregnancy at the time she was interviewed. Four women had had a total of 7 miscarriages, and 31 had ever had an abortion (a total of 51 abortions), implying that $53 \%$ of all pregnancies did not result in a live birth. When asked about their last three pregnancies, $63 \%$ of these pregnancies turned out to be either mistimed or unwanted at the time they occurred. Further analyses revealed that 10 women who had had a previous abortion had also had a live birth.

Even though $66 \%$ of these students did not want to get pregnant then, only $29 \%$ (11 students) were using a contraceptive method when they last got pregnant. The failed methods are as follows: condoms (4), emergency contraceptive pill (2), oral contraceptive pill (1), spermicide (1), withdrawal (2) and rhythm (1). More than half of those students, who did not want to get pregnant, were not using a contraceptive method.

\subsection{Experiences with HIV/AIDS}

Thirty-five percent of the respondents knew someone who was suffering from or who has died of HIV/AIDS. A quarter of the respondents reported having a family member other than a parent or sibling with HIV/AIDS, while the majority of cases reported that the victim was a friend, acquaintance or neighbour. Only one respondent admitted to living with HIV.

Fully, $18 \%$ worry that they might be HIV positive. Among those who had ever had sex, 27\% worry that they might be HIV positive. Many students (41\%) would like to undergo VCT and knew where to get tested; yet only $12 \%$ report having had the test. The majority of those tested (44\%) had gone for testing on their own accord, $30 \%$ at the request of a medical staff 
or VCT counsellor, and $24 \%$ had been tested as a requirement for funding, scholarship or visa application. Students who had been tested on their own accord had done so irrespective of whether they had ever had sex, or whether they knew someone suffering from HIV/AIDS.

\section{FACTORS INFLUENCING REPRODUCTIVE HEALTH DECISIONS \& SEXUAL BEHAVIOUR}

\subsection{Key persons/ communication/ discussions}

According to the FGDs, students on campus are being coerced into early sexual activity because they are seen as "deft", "kolo" or "yawa" (i.e. not trendy or fashionable), by their counterparts on campus. Others feel like engaging in sexual activity after hearing the conversations of their roommates and other friends. Yet, others still are left with the impression that if they complete Level 400 (final year of a first degree) without a boyfriend then the prospects of getting into a relationship are rather slim. Many of the female students who engage in sexual relations with their boyfriends do so "to prove to the men that they love them" or "with the hope of keeping the men interested" in the relationship. Some have sex with "guys on campus for the fun of it" or in order to enjoy their new found freedom. Many ladies who "can't afford a certain standard of living, yet want to be like others" tend to sleep with "sugar daddies" or "exters" (external boyfriends) who in turn support them financially.

Some $16 \%$ of students had ever been advised by a health worker about contraceptive methods. One-third of these discussions had been with a doctor or nurse/midwife. Students tended to discuss family planning, pregnancy and abortion with friends and relatives who themselves may not have adequate information on these issues (see Table 10).

A previous discussion held with a husband/partner seemed to have a greater impact on reproductive health decisions than those held with a family member, friend, or health worker. In fact, there was no significant link between having had a discussion with a family member, friend or health worker, and the probability of using contraceptives or opting to have an abortion.

However, as shown in Table 11, talking to a husband/partner at least once in the 12 months preceding the survey, led to a $150 \%$ increase in contraceptive use. Female students who had discussed contraception with their partner only once in the 12 months preceding the study 
were approximately four times as likely to use contraception when compared to those who had never had a previous discussion with their partners.

A student who had talked to her sexual partner about contraception at least once over the past twelve months was twice as likely to opt for an abortion, in case she got pregnant, compared to one who had never talked to her partner. This decision remained the same irrespective of whether the relationship with her partner was sexual or not. This is not to suggest that there is a direct link between the two variables. However, discussing contraception with one's partner may indicate the desire to postpone or prevent pregnancy, thus increasing the probability of opting for an abortion in case of an unintended pregnancy.

Table 10: Key persons with whom students discuss RH issues

\begin{tabular}{|l|r|}
\hline Statement/ Key persons & \multicolumn{2}{|c|}{$\begin{array}{c}\text { Percent of } \\
\text { Respondent }\end{array}$} \\
\hline Ever advised by health worker about FP methods & 16.7 \\
\hline Who $\mathbf{4 8 0})$ & \\
Doctor & 32.2 \\
Nurse/midwife & 31.1 \\
Family Planning worker & 23.3 \\
Social worker & 7.8 \\
Pharmacist & 5.6 \\
\hline Discussed FP with friends or relatives in last 12 months (n=480) & 36.3 \\
\hline Who (n=174) & \\
Friends on campus & 46.1 \\
Friends outside campus & 20.2 \\
*Husband/ Partner & 9.7 \\
Mother & 8.6 \\
Sister & 7.5 \\
Other relative (includes father or brother) & 6.4 \\
\hline
\end{tabular}

* Further analysis of responses revealed that $44.3 \%$ (rather than $9.7 \%$ ) of the students had talked to a husband /partner about using a contraceptive method in the last 12 months. These are reflected in the figures for friends on or off campus as well as other relatives, consequently swelling those figures.

Table 11: Effect of discussions with partner on RH decisions

\begin{tabular}{|c|c|c|c|c|c|c|c|}
\hline \multirow{2}{*}{$\begin{array}{l}\text { Frequency of } \\
\text { discussions with } \\
\text { husband/partner }\end{array}$} & \multicolumn{2}{|c|}{$\begin{array}{c}\text { *Current contraceptive } \\
\text { use }\end{array}$} & \multirow{2}{*}{$\begin{array}{l}\text { Percent } \\
\text { of total } \\
(n=147)\end{array}$} & \multicolumn{3}{|c|}{ *Decision to have an abortion } & \multirow{2}{*}{$\begin{array}{l}\text { Percent } \\
\text { of total } \\
(n=479)\end{array}$} \\
\hline & $\begin{array}{c}\text { Not } \\
\text { currently } \\
\text { using } \\
\end{array}$ & $\begin{array}{l}\text { Currently } \\
\text { using }\end{array}$ & & No & Yes & Not sure & \\
\hline $\begin{array}{l}\text { Never talked to } \\
\text { partner }\end{array}$ & 76.0 & 24.0 & 34.0 & 80.7 & 9.7 & 9.7 & 73.5 \\
\hline Once & 20.0 & 80.0 & 6.8 & - & - & - & - \\
\hline Twice & 46.2 & 53.8 & 8.8 & - & - & - & - \\
\hline More often & 31.1 & 69.9 & 50.4 & - & - & - & - \\
\hline At least once & 38.1 & 61.9 & 66.0 & 67.7 & 22.0 & 10.2 & 26.5 \\
\hline
\end{tabular}

* Significant difference between all groups at $\mathrm{p}<0.05$ 


\subsection{Perceptions}

Among all the respondents, $84.3 \%$ thought that female students on campus deal with the problem of unintended pregnancy by having an abortion; less than half of the respondents also thought that a student would keep a pregnancy while in school. Only $20 \%$ thought that a student would defer her course to have a baby, and very few (4\%) thought that a student would drop out of the university (see Table 12). Indeed, this clearly reflects the responses obtained from the individual interviews where, as described in section $5.3,78 \%$ of unwanted/unintended pregnancies did not result in a live birth.

Additionally, respondents thought that financial difficulties, refusal of partner to take responsibility for a pregnancy, school/career ambitions, stigma/peer pressure/disgrace and lack of parental support were factors that were important enough to possibly influence a student's decision to opt for an abortion.

Table 12: Students' perception of factors influencing a student's (hypothetical) decision to abort a pregnancy

\begin{tabular}{|l|c|}
\hline Factor & $\begin{array}{c}\text { Percentage of } \\
\text { cases (n=475) }\end{array}$ \\
\hline Financial reasons & 55.2 \\
Partner refuses responsibility/ withdraws & 47.2 \\
School/ career ambitions & 45.7 \\
Stigma/ peer pressure/ disgrace & 44.4 \\
Not yet married & 19.8 \\
Psychological readiness & 17.1 \\
Lack of parental support/care & 25.1 \\
Fear of parents & 15.8 \\
Morals/upbringing/religious reasons & 17.7 \\
Health reasons/fear of complications or death & 15.4 \\
Too young/immature & 10.3 \\
Child was unwanted/already had preferred number of children & 8.0 \\
Parental pressure & 5.9 \\
Rape & 4.8 \\
\hline
\end{tabular}

\subsection{Previous experiences}

\section{Effect on decision to have an abortion}

A student's perception of which decision they would make if faced with an unintended pregnancy was found to be influenced by past experiences, including personal sexual and abortion experience, as well as having a friend who had succeeded in obtaining an abortion 
(Table 13). The findings also suggest that, whereas $28 \%$ of sexually active students would prefer to abort the baby if faced with a pregnancy, only $31(6.5 \%)$ of the students admitted to having ever performed an abortion. The $28 \%$ of sexually active students preferring to have an abortion may actually reflect the reality. ${ }^{7,8}$ As expected, a student who had had a previous abortion was more likely (approximately 4 times as likely) to have another abortion. ${ }^{1}$ However, none of those students who had ever given birth would opt to have a subsequent abortion. This was probably because all, but one of these students, were married. Among those who had ever had sex, the likelihood of opting for an abortion decreased significantly with age. This decrease was most remarkable beyond age 24 .

Table 13: Factors influencing a (hypothetical) decision to have an abortion

\begin{tabular}{|c|c|c|c|c|}
\hline \multirow[t]{2}{*}{ Variable/ Response categories } & \multicolumn{3}{|c|}{$\begin{array}{l}\text { If you became pregnant as a student } \\
\text { would you opt to have an abortion }(\%)\end{array}$} & \multirow{2}{*}{$\begin{array}{l}* * \text { Total } \\
\text { number in } \\
\text { category }\end{array}$} \\
\hline & No & Yes & Not sure & \\
\hline $\begin{array}{l}\text { *Sexual experience } \\
\text { Never had sex } \\
\text { Not sexually active } \\
\text { Sexually active }\end{array}$ & $\begin{array}{l}81.9 \\
74.0 \\
63.2\end{array}$ & $\begin{array}{r}8.4 \\
15.4 \\
27.6\end{array}$ & $\begin{array}{r}9.7 \\
10.6 \\
9.2\end{array}$ & $\begin{array}{r}299 \\
104 \\
76\end{array}$ \\
\hline $\begin{array}{l}\text { *Friend had an abortion } \\
\text { No } \\
\text { Yes }\end{array}$ & $\begin{array}{l}79.4 \\
73.3\end{array}$ & $\begin{array}{l}10.0 \\
18.2\end{array}$ & $\begin{array}{r}10.6 \\
8.5\end{array}$ & $\begin{array}{l}301 \\
176\end{array}$ \\
\hline $\begin{array}{l}\text { *Has had a previous abortion } \\
\text { No } \\
\text { Yes }\end{array}$ & $\begin{array}{l}78.6 \\
55.2\end{array}$ & $\begin{array}{l}11.1 \\
41.4\end{array}$ & $\begin{array}{r}10.2 \\
3.4\end{array}$ & $\begin{array}{r}449 \\
29\end{array}$ \\
\hline $\begin{array}{l}\text { *Has ever given birth } \\
\text { No } \\
\text { Yes }\end{array}$ & $\begin{array}{l}65.8 \\
94.7\end{array}$ & $\begin{array}{r}23.4 \\
0\end{array}$ & $\begin{array}{r}10.8 \\
5.3\end{array}$ & $\begin{array}{r}158 \\
19\end{array}$ \\
\hline $\begin{array}{l}\text { *Age group } \\
<20 \\
20-24 \\
25-29 \\
30+\end{array}$ & $\begin{array}{l}28.6 \\
63.7 \\
91.7 \\
88.0\end{array}$ & $\begin{array}{r}57.1 \\
24.2 \\
8.3 \\
4.0\end{array}$ & $\begin{array}{r}14.3 \\
12.1 \\
0 \\
8.0\end{array}$ & $\begin{array}{r}7 \\
124 \\
24 \\
180\end{array}$ \\
\hline
\end{tabular}

Underlying reasons for having abortion

Table 14 presents the percentage distribution of the students who had ever had an abortion by the main reason given for having the abortion. For many female students, more than one factor contributed to the decision to have the abortion. Since it may be difficult in many situations for a woman to identify a single factor as the most important one, the question posed simply asked why they had had each abortion, thus allowing students to give multiple 
reasons. Commonest reasons given were 'still in school', 'fear of parents' and 'child unwanted'.

Table 14: Percentage distribution of women who had ever had an abortion, by main reason given for seeking abortion.

\begin{tabular}{|l|r|}
\hline Reason & $\begin{array}{c}\text { Percent of } \\
\text { responses }(\mathrm{n}=31)\end{array}$ \\
\hline Financial & 10.3 \\
\hline Still in school & 51.7 \\
\hline Not married & 3.4 \\
\hline Stigma/disgrace/peer pressure & 3.4 \\
\hline Fear of parents & 31.0 \\
\hline Too young & 13.8 \\
\hline Health reasons & 10.3 \\
\hline Pregnancy/ child unwanted & 34.4 \\
\hline
\end{tabular}

\section{Economic reasons}

The importance of education as the main reason for their seeking an abortion was evident in Table 14. Over $50 \%$ of the students who had ever had an abortion indicated that they were still in school at the time of abortion. . They tended to explain this response by saying that the baby would disrupt schooling or that they were not working or still being cared for by their parents. In a further $10 \%$ of cases, students specifically said they could not afford to properly care for a child (financial), since neither they nor their partner was employed at the time.

A student's financial status was measured by their source of support while on campus as well as their involvement in an income generating activity. Contrary to expectations that a student's source of financial support could impact sexual behaviour, there was no evidence (from the study) to support this nor was there a significant relationship between source of financial support while in school and contraceptive use or to the decision to have an abortion. Additionally, no clear association emerged between students' educational attainment or years of stay on campus and the decision to use contraception, or the main reasons for seeking an abortion.

\section{Pregnancy or child unwanted}

One-third of the students mentioned that the major reason for having an abortion was that the pregnancy or child was unwanted without explaining what they meant or why it was unwanted. It is assumed that this reason comprised the desire to postpone childbearing (or to stop childbearing among those with multiple births) as a result of other factors or circumstances that made the timing of the pregnancy undesirable (refer to Table 14). For 
example, students may particularly want to postpone an early birth where it disrupts education, until after university when they have a job or until they are married. They may think they are too young and therefore unable to emotionally and psychologically deal with a pregnancy or child rearing, especially if they are dependent on their parents.

\section{Fear of parents or age}

From the focus group discussions, it became clear that many of the students who had led previously sheltered lives (either at home with strict parents or in strict secondary schools) were rather naive, and when released into a relatively unsupervised environment, tended towards unsafe sexual behaviour, with its attendant consequences. Condom use, for example, was lowest among the under twenties (33.3\%), and highest (62.1\%) among the 20-24 year age group. One student said:

"Some students can be admitted to the university young........., they are also having boyfriends since it's [like] the order of the day. I think they lose focus once they come here, there is no parent to control them."

Another said:

"There is a lot of naiveté because they are young; ........ most come from good schools and homes where there is strictness and discipline. The freedom .......the immaturity, the flattery of having - you know how men are when they are chasing you."

A 46 year old master's student said:

“........there is a group from a particular secondary school. I think they are over disciplined. When they get on campus it is not for money or for clothing, but for fun. It's so bad that these girls, they are getting pregnant. Some are aborting and it is so pathetic. Because they are over disciplined in school, I think they are not given the chance to explore"

Some students also said that they were too young to get pregnant, or feared that their parents would object to the pregnancy. These were common primary reasons given among female students under 25 years. Thirteen percent of the students mentioned that being 'too young' was a factor in their decision to have an abortion. They were neither emotionally nor psychologically ready to take care of a child, nor to 'disrupt their lives. Contributing to the $31 \%$ who mentioned 'fear of parents' were those who feared their parents' objections, those who feared their parents would not support them emotionally, or that their parents would withdraw their financial support. No student mentioned that they had been pressurized by a parent to have an abortion. 


\section{Health reasons}

Health was mentioned as a main reason for seeking an abortion by $10.6 \%$ of female students. Though not specified, this was interpreted as 'maternal health risk' and may include risks to either physical or mental health. Another area of uncertainty is whether the potential health problem had been identified by a doctor or by only the student herself.

Because threat to maternal health was often mentioned as an exception to the abortion law, and is most frequently cited by medical practitioners when recommending a termination of a pregnancy to a woman, many students may have cited this reason because it is socially acceptable and provides a legal or moral justification for abortion. This is merely speculative, and is not to suggest that the pregnancy did not pose a real health threat to these students.

\section{Marital Status}

In this study, marital status was significantly linked to both contraceptive use and the decision to have an abortion. Fully, 3.4\% of women who had ever had an abortion talked about the fact that they did so because they were not married at the time of the pregnancy. Similarly, 3.4\% mentioned that carrying the pregnancy or having a baby at the time would have exposed them to stigmatization and disgrace, or that peer pressure had influenced their decision to have the abortion. Stigmatization was expected to come from school mates, relatives, and even religious associates/ church members basically because the woman was not properly married at the time of the pregnancy. Additionally, some students said that society frowned on premarital sex and childbearing outside marriage.

"The society....could push you to go for an abortion because ........people will look at you in some way and that will push you, you wouldn't like the embarrassment so you go in for the abortion."

A few indicated that if they had that child it could also jeopardize their chances of getting married in future.

"They chose the one they think will benefit them (abortion) because at least they are in the act but don't want to carry their babies to their wedding, or have issues before their wedding."

\section{Partner problems}


It was interesting to note that students did not mention partner problems as a reason for terminating a pregnancy, even though this had been mentioned by $47 \%$ of students as a possible reason in the event that they found themselves pregnant (refer to Table 12). Underlying this general perceived reason were such specific ones as "the partner threatened to abandon the woman if she gives birth", "continuing with the pregnancy would lead to a break-up", or that "the partner simply did not want the child". Some women combined these reasons with not being able to afford a baby, suggesting the importance of having a partner who could offer both emotional and financial support.

Only 12 students had had an abortion after entry into the university. Unfortunately, this number was too small to further examine by socio-demographic/ background variables.

\section{REPRODUCTIVE HEALTH SERVICES AVAILABLE TO STUDENTS AT THE UNIVERSITY OF GHANA}

\subsection{Family Planning services}

Even though only few (16\%) of the students had ever been advised by a health worker about contraceptive methods, it was clear that almost universally, students knew about contraceptive methods and where to get them. Students seem to get family planning information mainly from programs/adverts on television and radio, and by reading magazines, books and fliers. Additionally, a significant proportion (33\%) had been taught about contraception in senior secondary school (SSS) or through discussions with friends.

Many of the students $(68 \%)$ currently using a contraceptive method had acquired it from a pharmacy/ drug store (either on campus or within walking distance of the university), and only $10 \%$ from a private family planning centre or PPAG clinic, implying that $90 \%$ of the students had received minimal or no counselling with the purchase of the method. Majority had neither encountered difficulty nor expected to encounter any difficulty acquiring contraception. Only two students admitted that they had found it difficult approaching a pharmacy attendant to buy contraceptives. Both of these students mentioned that the attendant's attitude had left them embarrassed.

In spite of knowing about contraception and having easy access to these, students still desire and strongly favour the provision of counselling (98\%) and family planning services (80\%) on campus. The desired quality of services or education that should accompany the 
acquisition of contraception is therefore questionable, or may simply not be possible at these facilities.

A commonly mentioned facility on campus is "Combaceph", a well-woman clinic offered at the School of Nursing on campus, even though only a handful of students had ever been there. Reasons given was that they thought services were only provided during nursing week celebrations, as the service was not advertised until then. Students also mentioned the Student's Clinic but not the University Hospital as a possible facility for FP services, but had no idea if such services were offered there, even though they have paid fees for health care at the hospital.

\subsection{STI Services}

Students would most readily seek care at any hospital or polyclinic (both government and privately run), if they suspected or found that they had an STI, but said they would prefer better quality, more affordable and easily accessible facilities than those available to them. However, $9 \%$ of the students would rather go to a friend, relative, herbalist or church for help. Only two students admitted that they did not know what to do if they had an STI.

As high as $77.7 \%$ of all respondents knew where to get VCT for HIV. Students who had ever been tested had done so mostly at a government hospital (55\%), at a private hospital or clinic $(35 \%)$ or even on campus during a hall week celebration (10\%). Only one student admitted to being tested at the University Hospital. She had done so because it was part of the entry requirements by the UG.

\subsection{Abortion Services}

Thirty seven percent of all students knew where to get an abortion, both from past experience and from the experiences of friends who had ever had an abortion. One-third of the facilities mentioned were outside Greater Accra region. Since no question had been asked about the student's permanent place of residence, it was difficult to determine whether students travel long distances for terminations or whether these facilities are merely close to their permanent place of residence (when they needed the abortion).

Abortions had been sought mostly from private facilities outside campus. Only six students who had ever had an abortion would specify the name of the facility where the abortion was done (even though they had readily mentioned names of facilities where a friend had had an 
abortion, indicating that they indeed knew a facility where they could get an abortion). Three of these facilities were outside Accra.

All students who admitted to performing the abortion at home, on campus, or at a friend's house (10\%), had done so with a pill (unnamed) or with Cytotec, which they had acquired at a pharmacy or at a hospital. Twelve students would neither state how or where the pregnancy had been terminated.

\section{ATTITUDES OF STUDENTS TO REPRODUCTIVE HEALTH SERVICES}

Respondents were asked whether sexually active university students should be provided with certain types of health services beside those provided at the university hospital. They had to indicate if they strongly favour, favour, don't favour, strongly oppose the services, or if they were not sure whether the service was necessary. They were also asked to give reasons why they had arrived at a particular decision.

Almost every student interviewed stated that reproductive health counselling (98\%) and family planning services (80\%) are vital to students' well being on campus. Among these, $78 \%$ said that they strongly favoured the provision of RH counselling services on campus, while $38 \%$ strongly favoured the provision of family planning services because they are both educative and preventative. According to the students, such services would help reduce the incidence of reproductive health problems among students while they were on campus and also in their future sexual and marital experiences, as well as help them make informed choices, practice safe sex and even lead to a subsequent reduction in unintended pregnancy, STIs and induced abortions.

Only half of the students favoured the provision of antenatal care (ANC), delivery services and postnatal care (PNC) to students on campus. Apart from being extremely useful to the married students on campus, they thought that such services would also help to ease the burden on unmarried students who find themselves pregnant on campus, and could even help reduce the incidence of induced abortions among unmarried students.

Even though more than one-third of the students thought that excellent post-abortion care (PAC) was important to help those who run into such problems, only $17 \%$ would like abortion services to be made available to students, since they assumed the provision of such 
services was likely to encourage promiscuity and unsafe sexual practices, and subsequently increase the incidence of abortion among students. They stressed the need for a facility to counsel pregnant students, and assist them in deciding how to resolve unintended pregnancy, so that they would not resort to the advice of friends, male partners or relatives. Even students who had ever had an abortion said it would have been less stressful if they had access to expert and confidential counsellors. The few who would like to see PAC services thought that it would help reduce the incidence of unsafe or illegal abortions if post abortion care was incorporated into the service. Other students thought that some form of service is important to help prevent complications and deaths from unsafe abortions and to offer counselling and FP services to victims, in order to prevent the need for subsequent or repeated abortions. It is interesting to note that only $37 \%$ of those students who favoured or strongly favoured the provision of abortion services, thought that they would actually opt for an abortion if they were to become pregnant as students.

Almost universally, students desire VCT for HIV as well as up-to-date STI plus HIV screening as well as treatment. They thought that easy accessibility to VCT would encourage students to know their HIV status, offer students vital education as well as create awareness about HIV/AIDS on campus, and thus help curb the spread of the disease on campus. Ten percent of the students, who had ever been tested, did so voluntarily because the facility was offered during a hall week celebration on campus, 55\% got tested at a government hospital or clinic, and $35 \%$ at a private health facility. Many would have used a school facility if it was available and more affordable.

Additionally, the majority of respondents were of the view that substance abuse was related either directly or indirectly to sexual practices, and that drug abuse centres are necessary. More than one-third (39\%) of students said that they strongly favour the provision of counselling and treatment centres since drug abuse was a serious problem on campus, and were of the view that some of their colleagues (both male and female) would benefit from this.

\section{RESOLUTION OF UNINTENDED PREGNANCY}

The majority of unintended pregnancies result in induced abortions, irrespective of the legal status of abortions in any country. ${ }^{9,10}$ In countries where abortions are illegal, or perceived to be illegal, a large proportion of these induced abortions are unsafe, and especially so, where ethical, moral, and religious values and societal attitudes make many young and/or unmarried female students reluctant to carry a pregnancy or have an unplanned birth. ${ }^{11}$ 
The rates of unintended pregnancy and consequently induced abortions were expected to be high among this group of students. For example, according to a Zambian study, $81 \%$ of women hospitalized for abortion complications were students who did not want the pregnancy to interrupt their education. ${ }^{12}$ Similarly, a Ugandan study concluded that the bulk of abortion patients were young, single, of low parity and enrolled in either secondary school or university. ${ }^{13}$ " (Quoted from Bankole et al, 1998; Ref 9)

This study sought to understand how female students in a tertiary institution of education in Ghana resolved unintended pregnancies. We sought to determine how they navigate the myriad of personal, social and economic factors to arrive at a final decision.

\subsection{What students think they will do if pregnant}

All students were asked what they thought they would do if they found themselves currently pregnant. Various students interpreted this question as follows:
a. What decision to make
b. Who to seek help from
c. Where to go for help

Some chose to answer this question in more than one way. The entire spectrum of responses given is reflected in Table 15 .

Three quarters of the female students on UG campus would decide to keep the baby. This decision would be arrived at after confiding in their mother and/or boyfriend. Those who chose to speak to their father would tell him with the support of their mother or some other relative. "Other relative" also included those who would seek help from a cousin or aunty who is a nurse/ midwife). Generally, students who would rather confide in a friend (16\%) would probably do so in order to gain assistance for a termination (e.g. "choose to abort the baby" (14\%)).

Majority of the students (64\%) said if faced with the decision to have an abortion, they would not do so beyond 2 months gestation, and $94 \%$ would not chose to have an abortion beyond 3 months gestation due to the health risk and possible complications

\section{Table 15: What students would do if currently pregnant}

\begin{tabular}{|l|c|}
\hline Variable/ Response categories & $\begin{array}{c}\text { Percentage } \\
\text { of responses } \\
n=480\end{array}$ \\
\hline
\end{tabular}




\begin{tabular}{|l|c|}
\hline What decision to make & \\
Keep baby & 74.9 \\
Abort baby & 13.7 \\
Be confused/Panic & 9.6 \\
Cry/be sad/be disappointed & 5.0 \\
Feel guilty/blame herself & 0.9 \\
Check for HIV & 0.3 \\
Defer my course & 5.3 \\
Wear a ring to avoid ridicule & 0.3 \\
Get married quickly & 2.6 \\
Pray & 0.9 \\
& \\
\hline Who to tell/ talk to & \\
Mother & 67.4 \\
Father & 43.2 \\
Boyfriend & 65.6 \\
Friends & 15.9 \\
Other relative & 12.8 \\
Counselling from health worker & 4.0 \\
Counselling from pastor & 2.2 \\
Counsellor /elderly person & 4.4 \\
No one/self help & 0.4 \\
\hline Where to go or help & \\
Any hospital & 73.6 \\
Doctor/specialist & 23.6 \\
Pharmacy shop & 4.2 \\
Travel outside Ghana & 4.2 \\
& \\
\hline
\end{tabular}

*Some respondents gave multiple answers, making the totals greater than 100.

\subsection{What their (student's) friends have done}

A total of 120 students (25\%) had at least one (student) friend who had ever had an abortion; $11.7 \%$ of these students had more than one (student) friend who had ever had an abortion. In $72 \%$ of the cases, the pregnancy had been terminated by two months gestation, $33 \%$ said the pregnancy had been terminated at three months gestation, and a further $4.2 \%$ had friends who had a termination at 4 months gestation. Only $43.2 \%$ of such friends were students on UG campus, the remainder were students from other educational institutions. A total of 104 students $(87 \%)$ knew where their friend had obtained the abortion. Only 4 students knew about a student on UG campus who had died following an abortion

\subsection{What students have actually done when faced with unintended pregnancy}

Among students who had ever had sex, 17\% (31 students) had ever attempted to have an abortion. All of these students admitted that they had ever succeeded in having an abortion. Among the 31 students, 19 had attempted and succeeded in having a single (1) abortion; 8 students had aborted twice; 3 students had succeeded at all three attempts. One student 
admitted to 4 attempts, having succeeded thrice and failed to abort once. This implies that out of 110 pregnancies ever experienced by these students, $47 \%$ had been aborted.

Further analyses revealed that $67 \%$ of all students who had ever been pregnant had had at least one induced abortion, and that 10 women who had had a previous abortion had also had a live birth.

In $54 \%$ of the cases, students had terminated these pregnancies at one-month gestation; $36 \%$ of pregnancies had been aborted at two months, , 7\% and 3\% of pregnancies were terminated at three and four months gestation respectively. Only $40 \%$ of the terminations were done after entry into the University of Ghana. The decision to have an abortion is neither influenced by length of stay on campus nor year of study since admission to the UG.

When asked for the details of how and where these abortions were performed, three students declined to give details. Seventeen students described how (Table 16) and nineteen described where they had obtained the abortion (Table 17). Only 9 students each described both how and where they had obtained the abortion.

Table 16: Method by which some students obtained abortions

\begin{tabular}{|l|c|}
\hline Method & $\begin{array}{c}\text { Number } \\
(\mathrm{n}=31)\end{array}$ \\
\hline Cytotec & 12 \\
\hline Other pills & 2 \\
\hline Manual vacuum aspiration & 2 \\
\hline Dilatation and curettage & 1 \\
\hline Detail missing & 14 \\
\hline
\end{tabular}

Table 17: Places where some students had obtained abortions

\begin{tabular}{|l|c|c|}
\hline Location where abortion was done & $\begin{array}{c}\text { By the student's } \\
\text { friend }(\mathrm{n}=159)\end{array}$ & $\begin{array}{c}\text { By the student } \\
\text { herself }(\mathrm{n}=20)\end{array}$ \\
\hline Government hospital /polyclinic & 12.6 & 15.0 \\
\hline Private hospital/clinic & 34.6 & 55.0 \\
\hline At home/hostel/ friend's house & 19.5 & 20.0 \\
\hline Private doctor's residence & 0 & 5.0 \\
\hline Don't know/ detail missing & 33.4 & 5.0 \\
\hline
\end{tabular}

Of the students who had performed the abortion at home, twelve said they had used cytotec or some other pills. Besides these students, it is not known how the terminations were performed at home.

\section{DISCUSSION AND CONCLUSIONS}


Less than $0.8 \%$ of the students sampled had adequate knowledge about the menstrual cycle, while three quarters had some knowledge. Even fewer still could correctly say when a woman is most likely to get pregnant in a menstrual cycle. Almost all female students are aware of contraceptives, but may not necessarily be using an effective method. It is clear why students choose not to use contraception or resort to the use of ineffective methods. This stems from the fear that use of modern contraception, apart from condoms, may eventually lead to a difficulty to conceive, or even secondary infertility when a woman is ready to have a baby. Students generally had adequate knowledge of STIs and HIV. Reproductive health knowledge on the whole, and knowledge about unintended pregnancy and abortions in particular, seems to increase with the onset of sexual activity and even more so with marriage. This may be a combined result of greater access to FP counseling, and society's receptivity to communication about reproductive health matters among married people.

About $38 \%$ of female students in the University of Ghana are sexually active. Sexual activity among unmarried students is higher in the younger age groups, while condom use at last sexual intercourse is lowest among students aged less than 20 years. This may indicate a more liberal attitude to sex, and confirm the suspicion of older students that as younger (and therefore immature) students gain admission into universities, their naiveté leads to an increase in unsafe sexual behaviour within a relatively unsupervised environment, with the attendant risks of STIs, unintended pregnancy and induced abortions.

Unintended pregnancy is common among sexually active university students, mainly because of failure to consistently use effective contraceptive methods. Only $48 \%$ of sexually experienced students were using a contraceptive method at the time of the survey, predominantly the male condom. Twenty six percent (46 students) of sexually active students admitted to ever getting pregnant, yet only $10.6 \%$ (19 students) of this group had ever given birth. Students admitted that out of their last three pregnancies experienced, $63 \%$ were either mistimed or unwanted at the time it occurred. Overall, $46 \%$ of such unintended pregnancies ended up aborted and $6.4 \%$ miscarried. However these estimates may understate the true levels since premarital sex and pregnancy are still frowned upon in this society. Abortion is still a taboo subject, and many more students admit that they know at least one other student or friend who has ever terminated a pregnancy. The high rates of resorting to abortion by sexually active female students reflects the non-use of a contraceptive method at the time of occurrence of the last pregnancy in spite of inadequate knowledge of the fertile period of their menstrual cycles. 
The high proportion of unintended pregnancy and the estimated number ending in abortions are consistent with a desire for low fertility, given the opportunity costs, within an environment of significant sexual activity coupled with low contraceptive prevalence.

Evidence from the cross-sectional survey and FGDs carried out among these students suggests certain important factors which influence students' reproductive health decisions and which ultimately result in an abortion.

An analysis of the reasons students gave for having had an abortion shows that being in school is the commonest reason. Women who gain access to tertiary institutions of education have generally done so at great social and financial cost, and have great academic ambitions. To have a child, especially outside marriage, and probably without the financial and emotional support of a male partner, would mean jeopardizing all that they have hitherto worked for or aspired to be, and make nonsense of the investment made by their families and themselves. The other commonest reasons given were "pregnancy/ child unwanted" followed by "fear of parents".

Factors which significantly influenced their RH decisions, (i.e. the decision to use contraception or to have an abortion), include the age of the student, who the students had previously communicated or had discussions with on the subject, the perception that their counterparts were dealing with these issues in a certain way (group thought), or even having a friend who had taken a similar RH decision. A previous discussion with a husband or partner had a greater impact on RH decisions than those held with a family member or friend. Only $16 \%$ of the students had ever been advised by a health worker on these issues.

Once a student had given birth, the likelihood had she would use a certain type of contraceptive or have an abortion was reduced considerably. All but one of the students who had given birth was married. By extension, therefore, marital status plays a vital role in $\mathrm{RH}$ decisions of female students on campus.

These estimates of unintended pregnancy and abortion, as well as the factors influencing these, should help raise awareness of the difficulties that even highly educated women have in preventing pregnancies and abortions, especially with respect to inadequate access to contraceptive information and services. 
Reduction in the levels of unintended pregnancy will lower the incidence of [unsafe] abortions among female students, and thereby reduce the social, economic and health consequences these women experience.

\section{RECOMMENDATIONS}

Clearly, programs must be put in place to help female students prevent unintended pregnancy and to reduce the level of unsafe abortions. The initial focus should be on counseling and education regarding relationships, sex and reproductive health decisions, including abstinence as an important option.

To reduce unintended pregnancy and abortions, a comprehensive IEC campaign should focus on reducing fears and misconception about family planning by disseminating accurate, reliable and consistent messages among this group of women nationwide. Emphasis should be on correct and consistent use, side effects and effectiveness of the various methods.

The campaign should also focus on male students and other partners of female students, to increase their knowledge and understanding of contraception and their support for their female partners' contraceptive and abortion decisions. Emphasis should be placed on education about contraception and about prevention of STIs/HIV.

Provision of high quality, yet affordable student friendly reproductive health facilities is vital. These should be easily accessible and preferably integrated with other services to ensure confidentiality and avoid stigmatization. The ideal facility should offer

- Counseling, a vital and highly preventative element of health care

- Screening, including diagnosis and treatment of STI/HIV

- Family planning and contraceptive services,

- Access to safe abortion services; including comprehensive post abortion care. For students requiring treatment for post abortion complications it is important that this includes emotional as well as contraceptive counseling and services.

Further qualitative research is needed as a precursor to the establishment of suitable reproductive health facilities on or near campus, especially with respect to the situation or location of such a facility. A vital component of this should be research into the role and 
needs of male partners, in order to design and target educational material at this very important group.

More in-depth research is required among female students in tertiary institutions of education, as well as their partners, in order to deepen our understanding of the factors which influence reproductive health decision making, since this is likely to provide vital information in designing effective group-specific interventions. 


\section{References}

\footnotetext{
${ }^{1}$ Adanu RMK, Ntumy MN, Tweneboah E, Profile of women with abortion complications in Ghana. Tropical
} Doctor, 2005; 35:139-142

${ }^{2}$ Lassey AT and Wilson JB, Trends in maternal mortality in Korle-Bu Hospital, 1984-1994. Ghana Medical Journal, 1998; 32a: 910-916

${ }^{3}$ Okonofua F, Abortion and Maternal Mortality in the Developing World, Journal of Obstetric and Gynaecological Cancers, 2006; 28(11):974-979.

${ }^{4}$ Baiden F, Awini E and Clerk C, Perception of university students in Ghana about emergency contraception. Contraception, 2002; 66: 23-26

${ }^{5}$ Provisional National Defence Council (PNDC). Law 102: The Criminal Code (Amendment) Law. The Constitution of Ghana, 1985

${ }^{6}$ Ghana Statistical Service (GSS), Noguchi Memorial Institute for Medical Research (NMIMR), and ORC Macro. 2004. Ghana Demographic and Health Survey, 2003. Calverton, MD, USA: GSS,NMIMR, and ORC Macro.

${ }^{7}$ World Health Organization (WHO), Unsafe Abortion: Global and Regional Estimates of Incidence of and Mortality Due to Abortion With a Listing of Available Country Data, Third Edition, Geneva: WHO, 1998.

${ }^{8}$ Ahiadeke C, Incidence of induced abortion in southern Ghana. International Family Planning Perspectives, 2001; 27(2): 96-101, 108

${ }^{9}$ Bongaats J, Trends in unwanted childbearing I the developing world. Studies in Family Planning, 1997;28(4): 267-277

${ }^{10}$ The Alan Guttmacher Institute (AGI), Facts in Brief, Induced Abortion Worldwide, New York: AGI, 1999.

${ }^{11}$ Bankole A, Singh S and Haas T, Reasons Why Women Have Induced Abortions Evidence from 27 Countries. International Family Planning Perspectives, 1998; 24(3):117-127 \& 152

${ }^{12}$ Salter C, Johnson HB and Hengen N, Care for postabortion complications: saving women's lives, Population Reports, Series L, No. 10, 1997.

${ }^{13}$ Miremble FM, A situation analysis of induced abortions in Uganda, African Journal of Fertility, Sexuality and Reproductive Health, 1996; 1(1):79-80. 